INTERNATIONAL JOURNAL OF RESEARCHES IN BIOSCIENCES, AGRICULTURE \& TECHNOLOGY (C) VISHWASHANTI MULTIPURPOSE SOCIETY (Global Peace Multipurpose Society) R. No.MH-659/13(N) www.vmsindia.org

\title{
MICELLLAR INHIBITION OF IODINATION OF SALICYLIC ACID AND INVESTIGATION OF IODINATING SPECIES
}

\section{Batra V.R., ${ }^{2}$ Kapoor S.B., ${ }^{3}$ Narkhede P.V. and ${ }^{4}$ Patil D.B.}

\author{
1Sarvodaya MahavidyalayaSindewahi, Chandrpur (M.S) India \\ ${ }^{2} \mathrm{Art}$, Commerce and Science College, Tukum, Chandrapur (M.S) India \\ ${ }^{3}$ Rajiv Gandhi College of Engineering, Wanadongri, Nagpur (M.S) India \\ ${ }^{4}$ Government Institute of Science Nagpur (M.S) India \\ Email: kapoor.sushil2012@gmail.com
}

\begin{abstract}
The kinetics of iodiation of salicylic acid inhibited by micelle has been investigated in aqueous iodine and in the presence of cationic surfactant cetyltrimethyl ammonium bromide (CTAB) at $50^{\circ} \mathrm{C}$. The reaction followed first order kinetics with respect to salicylic acid and iodine. Increase in CTAB concentration decreases the specific reaction rate values. The specific reaction rate of iodination of salicylic acid, in absence of CTAB is found to be $2.57 \times 10^{-3} \mathrm{M}^{-1} \mathrm{~s}^{-1}$ at $50^{\circ} \mathrm{C}$. The iodinating species in micelle media have been discussed in detail. The possible schematic representation of interaction of reactants in micelle have been shown.
\end{abstract}

Keywords: Salicylic acid, Micelle, Iodination, Surfactant, Iodinating species

\section{Introduction:}

During last few decades the continuing research interest in the area of micelle formation and their role in the reaction catalysis and inhibition reflects its importance. The study of Fendler and Fendler ${ }^{1}$ and some books ${ }^{2-4}$ depicts the knowledge about micelles. Pseudophase model interprets the unimolecular and bimolecular reactions between uncharged species in aqueous solutions ${ }^{5-7}$. The increase in rate or decrease in rate are based on the mediam effect or concentration effect or both 7-9.

In case of reaction occurring in ionic micelles the charge neutralization at the micelle head groups remains constant as the micelle is formed. This concept is widely accepted in the kinetic analysis of large number of reactions between hydrophilic ions and neutral substrate, particularly in micelle of cetyltrimethyl ammonium bromide ${ }^{8-12}$, later on it has been shown that this kinetic treatment is failure with more hydrophobic counter ions, particularly micelle like cetyltrimethyl ammonium hydroxide and $\mathrm{CTAB}^{13}$.

From the kinetic and substrate solubilization data it appears that micellar media incorporates the reactant into micelle aggregates and brings it into proximity with reagent into bulk phase. It is then either electrostatically attracted to micelles or incorporated into micelle by chemical forces. This leads to increase in the rate of reactions. The rate of reaction also increases by stabilization of transition state. Alternatively micelle may solubilize the reactant or do not attract the reacting ions and leads to decrease in rate of reaction. The rate of reaction also decreases by stabilization of one of the product of reaction by change effect of the micelles. Hence the mechanism of the reaction can be cleared by explaining the charge effect of micelles ${ }^{14-19}$.

The paper present the effect of CTAB on the iodination of salicylic acid by iodine in aqueous solution and the details of the iodinating species involved in the iodination. Further, interaction of reactant in micelle has been represented.

\section{Material and methods:}

Chemicals: Deionized water after distillation in alkaline potassium permanganate was used as a solvent, salicylic acid, Iodine, sodium thiosulphate were of analytical reagent grade. The purity of CTAB was ascertained by the absence of minima in surface tension versus logarithm of concentration of CTAB 20 .

Critical micelle concentration (CMC): The conductometric technique was used to determine CMC value of CTAB with various concentrations in the reaction system. CMC was determined as a sharp decrease in a 
plot of specific conductivity versus concentration of surfactant. The value obtained was $1.0 \times 10^{-2} \mathrm{M}$ for CTAB.

Kinetics: Solution of iodine in sodium iodide solution was used as a iodination reagent. The reaction was carried out in presence of excess of iodide ion to minimize the effect of iodide ion formed during the reaction. The rate of reaction was determined with $250 \mathrm{~cm}^{3}$ of solution containing $5.0 \times 10^{-3} \mathrm{M}$ salicylic acid and $5.0 \times 10^{-3} \mathrm{M}$ of iodine in $5.0 \times 10^{-2} \mathrm{M}$ iodide at $50.0^{\circ} \mathrm{C}$. The extremely slow rate of reaction is responsible to use $50^{\circ} \mathrm{C}$ temperature. Unreacted iodine was estimated by titrating $25.0 \mathrm{~cm}^{3}$ of aliquote reaction mixture against standardized $2.5 \times 10^{-2} \mathrm{M}$ Sodium thiosalphate at various time intervals using freshly prepared starch as an indicater.

In order to investigate the effect of CTAB The rate measurements were also carried out in different concentrations of CTAB, ranging from $2.0 \times 10^{-2} \mathrm{M}$ to $5.0 \times 10^{-2} \mathrm{M}$

\section{Result and discussion:}

The specific reaction rate of iodination of salicylic acid by iodine was determined by titrating the unreacted iodine against $2.5 \times 10^{-2} \mathrm{M}$ sodium thiosulphate using starch as an indicator. The graph of $1 /\left[I_{2}\right]$ versus time is linear and indicates the second order kinetics. The specific reaction rate, $\mathrm{k}_{2}$ for iodination of salicylic acid is $2.57 \times 10^{-3} \mathrm{M}^{-1} \mathrm{~S}^{-}$ 1 at $50.0^{\circ}$ c.(Table- 1 and Fig. -1 )

Table1. Kinetics of the iodination of salicylic acid by iodine.

\begin{tabular}{|c|c|c|c|}
\hline Time (s) & $\begin{array}{c}\text { Volume of } \\
2.5 \times 10^{-2} \mathrm{M} \\
\text { Sodium } \\
\text { thiosulphat } \\
(\mathrm{mL})\end{array}$ & $\begin{array}{c}\text { Unreacted } \\
\text { lodine }\left[\mathrm{I}_{2}\right] \\
\left(10^{-3} \mathrm{M}^{-1}\right)\end{array}$ & $1 /\left[\mathrm{I}_{2}\right]\left(\mathrm{M}^{-1}\right)$ \\
\hline 0 & 16.0 & 5.00 & 200.0 \\
3600 & 15.2 & 4.75 & 210.0 \\
7200 & 14.6 & 4.56 & 219.3 \\
10800 & 14.1 & 4.41 & 226.7 \\
14400 & 13.6 & 4.25 & 235.3 \\
18000 & 13.0 & 4.06 & 246.3 \\
\hline
\end{tabular}

\section{NOTE:}

Salicylic acid $]=5.0 \times 10^{-3} \mathrm{M},[$ Iodine $]=5.0 \times 10^{-3}$ $\mathrm{M}$,

[Salicylic Iodide $]=5.0 \times 10^{-2} \mathrm{M}$, Temperature $=$ $50^{\circ} \mathrm{C}$

Slope of the graph $1 /\left[\mathrm{I}_{2}\right]$ versus time=Specific reaction rate, $\mathrm{k}_{2}=2.5 .7 \times 10^{-3} \mathrm{M}^{-1} \mathrm{~s}^{-1}$

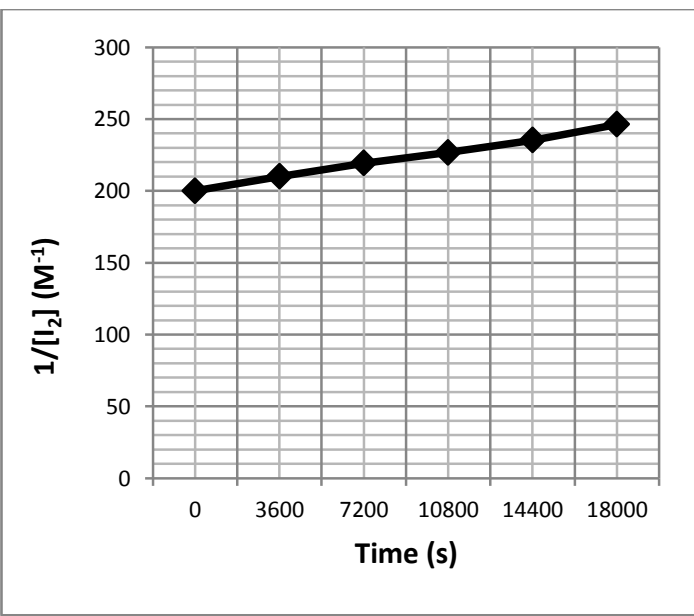

Fig. 1 Kinetics of the lodination of salicylic acid by lodine.

The effect of micellar media on the rate of reaction was investigated. For this purpose, CMC of CTAB were determined in the reaction system and found to be $1.0 \times 10^{-}$ ${ }^{2} \mathrm{M}$ from the inspection of equivalent conductance-surfactant concentration plots.

The $1 /\left[\mathrm{I}_{2}\right]$ versus time plots was plotted during the reaction of $5.0 \times 10^{-3} \mathrm{M}$ salicylic acid and iodine solutions in the presence of CTAB in different concentrations in order to see its effect in second order kinetics (Tables 2)

The dependence of second order rate constant, $\mathrm{k}_{2} \mathrm{On}$ CTAB concentration has been illustrated in Fig. 2

The specific reaction rate decreases from $2.22 \times 10^{-3} \mathrm{M}^{-1} \mathrm{~s}^{-1}$ to $1.17 \times 10^{-3} \mathrm{M}^{-1} \mathrm{~s}^{-1}$ at $50.0^{\circ} \mathrm{C}$ by increasing the concentration of CTAB from $2.0 \times 10^{-2} \mathrm{M}$. From this it appears that the inhibition of iodination take place (Table-2, Fig.-2).

Table 2. Dependence of specific reaction rate, $\mathrm{k}_{2}$ on the concentration of CTAB.

\begin{tabular}{|c|c|}
\hline $\begin{array}{c}\text { Concentration of } \\
\text { CTAB }\left(10^{-2} \mathrm{M}\right)\end{array}$ & $\begin{array}{c}\text { Specific reaction rate, } \mathrm{k}_{2} \\
\left(10^{-3} \mathrm{M}^{-1} \mathrm{~s}^{-1}\right)\end{array}$ \\
\hline 00 & 2.57 \\
2.0 & 2.22 \\
3.0 & 1.83 \\
4.0 & 1.50 \\
5.0 & 1.17 \\
\hline
\end{tabular}




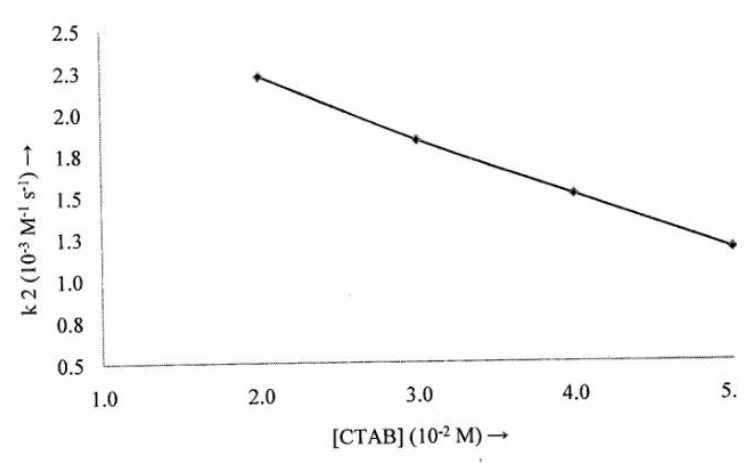

Fig.-2: Dependance of specific reaction rate, $\mathrm{k}_{2}$ on concentration of cetyltrimethyl ammonium bromide.

This can also be confirmed from Table3. The result of this table shows that the solubilization of iodine in miceller phase decreases with increasing the concentration of CTAB. It also supports the inhibition of iodination.

Table-3.Solubilization of Iodine in Micellar phase

\begin{tabular}{|c|c|c|c|c|}
\hline \multirow{2}{*}{$\begin{array}{c}\text { Time } \\
(\mathrm{s})\end{array}$} & \multicolumn{3}{|c|}{ Fraction of iodine solubilized inmicellar phase $(\mathrm{fm})$} \\
\cline { 2 - 5 } & {$[\mathrm{CTAB}]=2.0 \times 10^{-3} \mathrm{M}$} & $3.0 \times 10^{-3} \mathrm{M}$ & $4.0 \times 10^{-3} \mathrm{M}$ & $5.0 \times 10^{-3} \mathrm{M}$ \\
\hline 3600 & 0.034 & 0.062 & 0.070 & 0.078 \\
7200 & 0.070 & 0.122 & 0.122 & 0.142 \\
10800 & 0.100 & 0.152 & 0.176 & 0.196 \\
14400 & 0.130 & 0.194 & 0.218 & 0.242 \\
18000 & 0.142 & 0.230 & 0.260 & 0.286 \\
& & & & \\
\hline
\end{tabular}

Note [CTAB] is the concentration of cetyltrimethyl ammonium bromide.

The rate of iodination of salicylic acid changes in micellar media than in aqueous media. This change in reaction rate depends on the structure of micelle, salicylic acid. In particular on their properties such as polarity, electronic charge and hydrophobicity.

The kinetics results and solubilization of iodine in micellar media shows that in the presence of CTAB where micelle solubilize the iodine but repel the reagent in bulk phase or do not attract them effectively, the reactants are separated or do not oriented properly and as a result the iodination is inhibited. The extent of inhibition depends upon how deeply the substrate buried in the micelle. This shows that all the factors affecting the solubilzation of substrate and reactive ion binding also affects the rate of iodination in micellar solution. The conceptual model is shown in Fig. 3

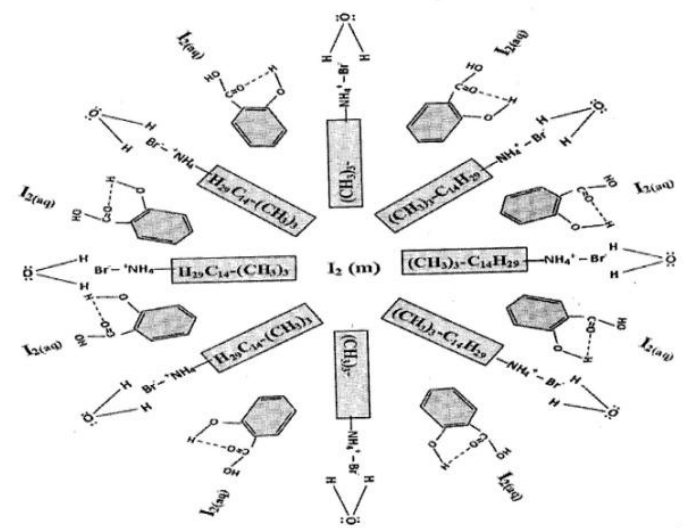

Fig.-3: Conceptual model of iodination of salicylic acid by iodine inhibited by cetyltrimethyl ammonium bromide micelle.

Another possibility for decrease in rate of iodination is the stabilization of ground state as a result of the charge effect of micelles. The stabillzation of ground state, however, results in the inhibition. Thus, mechanism of reaction can also be elucidated by utilizing charge effect.

There is controversy21-25 on the iodinating agent in the iodination, according to the following proposed mechanism.

$$
\begin{aligned}
& \mathrm{I}_{2}+\mathrm{H}_{2} \mathrm{O} \rightleftharpoons \mathrm{H}_{2} \mathrm{OI}^{+}+\mathrm{I}^{-} \\
& \mathrm{H}_{2} \mathrm{OI}^{+}+\mathrm{ArH} \rightleftharpoons \mathrm{ArH}^{+}+\mathrm{H}_{2} \mathrm{O} \\
& \mathrm{ArHI}^{+}-\mathrm{Arl}+\mathrm{H}^{+}
\end{aligned}
$$

Mechanism-I

$$
\begin{aligned}
& \mathrm{ArH}+\mathrm{I}_{2} \rightleftharpoons \mathrm{ArHI}^{+}+\mathrm{I}^{-} \\
& \mathrm{ArHI}^{+} \rightarrow \mathrm{ArI}+\mathrm{H}^{+}
\end{aligned}
$$

Mechanism-II

The equilibrium with iodine and tri-iodide can be represented as

$$
\mathrm{I}_{2}+\mathrm{I}^{-} \underset{\mathrm{kb}_{\mathrm{b}}}{\stackrel{\mathrm{kf}_{\mathrm{I}^{-}}}{\rightleftharpoons}}
$$


This equilibrium is rapidly established and either $\mathrm{I}_{2}$ or both could be the iodinating agents. The interconversion of $\mathrm{I}_{2}$ and $\mathrm{I}_{3}$ is very fast. The forward rate constant for this reaction is $4.1 \times 10^{-10} \mathrm{M}^{-1} \mathrm{~s}^{-1}$ while the backward rate constant is $7.6 \times 10^{-7} \mathrm{~s}^{-1}$. Therefore the rate of tri-iodide formation is

$$
\begin{aligned}
\text { Rate } & =\mathrm{k}_{\mathrm{f}}\left[\mathrm{I}_{2}\right]\left[\mathrm{I}^{-}\right] \\
& =4.1 \times 10^{10}\left[\mathrm{I}_{2}\right] \times 5.2 \times 10^{-2} \\
& =2.05 \times 10^{9}\left[\mathrm{I}_{2}\right]
\end{aligned}
$$

The rate of dissociation of tri-iodide is

$$
\begin{aligned}
\text { Rate } & =\mathrm{k}_{\mathrm{b}}\left[\mathrm{I}_{3}{ }^{-}\right] \\
& =7.6 \times 10^{7}\left[\mathrm{I}_{3}{ }^{-}\right]
\end{aligned}
$$

Since the equilibrium constant of the reaction is very high, namely 830 , one can consider that $\left[\mathrm{I}_{2}\right] \approx\left[\mathrm{I}_{3}\right]$

The rate of iodination of salicylic acid $=$ $\mathrm{k}_{2}$ [salicylic acid] [ $\left.\mathrm{I}_{2}\right]$

Therefore rate of iodination

$$
\begin{aligned}
& =2.57 \times 10^{-3} \times 5.0 \times 10^{-3}\left[\mathrm{I}_{2}\right] \\
& =1.29 \times 10^{-5}\left[\mathrm{I}_{2}\right]
\end{aligned}
$$

The rate of formation of tri-iodide ion is 1.59 $\times 10^{14}$ times higher and rate of dissociation of tri-iodide ion is $5.89 \times 10^{12}$ times higher than the rate of iodination of salicylic acid. From these considerations it appears that it is equally possible that the iodinating species may be molecular iodine or triiodide ion. On the other hand, if tri-iodide is the iodinating agent, the specific reaction rate should have been accelerated with increasing with increasing the iodide concentration. But in present case, inverse dependence of specific reaction rate on iodide concentration has been observed. Hence the tri-iodide cannot be the reacting entity, which obviously suggested that the molecular iodine is the iodinating agent. Iodine is known to be hydrolyzed according to the equation

$$
\mathrm{I}_{2}+\mathrm{H}_{2} \mathrm{O} \underset{\mathrm{K}}{\rightleftharpoons} \mathrm{HOI}+\mathrm{H}^{+}+\mathrm{I}^{-}
$$

The first order forward velocity constant of this reaction is $3.0 \mathrm{~s}^{-1}$ and third order velocity constant of the reverse reaction is $4.4 \times 10^{12} \mathrm{M}^{-2} \mathrm{~s}^{-1}$.

Since the backward velocity constant of this reaction is very much higher than the forward velocity constant, the equilibrium concentration of hypoiodus acid is much less than that of molecular iodine. Nevertheless, if hypoiodus acid is yet considered as the iodinating agent, the rate of backward reaction in aqueous solution is (Rate)b = $\mathrm{k}_{\mathrm{b}}[\mathrm{HOI}]\left[\mathrm{H}^{+}\right]\left[\mathrm{I}^{-}\right]$

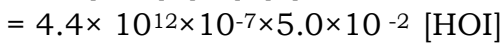

$$
\begin{aligned}
& =2.2 \times 10^{4}[\mathrm{HOI}]
\end{aligned}
$$

The iodination of salicylic acid is second order reaction, therefore the rate of iodination by hypoidous acid can be represented as.

$$
\begin{aligned}
\begin{aligned}
(\text { Rate })_{\text {Id }} & =\mathrm{k}_{2} \quad[\text { Salicylic acid }][\mathrm{HOI}] \\
& =2.57 \times 10^{-3} \times 5.0 \times 10^{-3}[\mathrm{HOI}] \\
& =1.29 \times 10^{-5}[\mathrm{HOI}]
\end{aligned} \\
\therefore \text { (Rate) })_{\text {Id }}=1.29 \times 10^{-5}[\mathrm{HOI}]
\end{aligned}
$$

(Rate)b $2.2 \times 10^{4}[\mathrm{HOI}]$

$$
(\text { Rate })_{\mathrm{Id}}=5.86 \times 10^{-10}(\text { Rate }) \mathrm{b}
$$

or $1.71 \times 10^{9}$ (Rate) Id $\quad=($ Rate $) \mathrm{b}$

Thus the rate of conversion of HOI to I2 is about $1.71 \times 10^{9}$ time higher than the rate of iodination of salicylic acid. It indicates that all $\mathrm{HOI}$ is converted to $\mathrm{I}_{2}$ before reacting with salicylic acid. Therefore, the molecular iodine is the only iodinating agent.

\section{Reference:}

Fendler, E.J and Fendler, J.H.,Advences in phys. org. Chem., 8, 271 (1970).

Fendler, J.H and Fendler, E.J, "catalysis in micellar and Macromolecular systems."Academic press, New York, (1975). Cordes, E.H. (Editor), "Reaction kinetics in Micelles,” plenum pub.' New York, (1973)

Mittal, K.L., "Micellization, solubilization and Microemulsions".Plenum press, Now York, Vol.2, (1977).

\section{Maqsood Ahmad Malik, \\ SulimanNaserBasahel, Abdullah} YousifObaid, Zaheer khan. 2010, Oxidation of tyrosine by permanganate in presence of cetyltrimethylammonium bromide. Colloids and surfaces B: Biointerfaces 76, 346-352.[CrossRef]

Maqsood Ahmad Malik, Shaeel Ahmed ALThabaiti, Zaheer khan.2009.Kintics of oxidation of $\mathrm{d}$ - glucose by permanganate in aqueous solution of cetyltrimethylammonium bromide. Colloids and Surfaces A: Physicocbemical and Engineering Aspects 337, 9-14. [CrossRef].

Sang Munjeong, Young Chang Byun, Jong Hyun Chae,Won-Ho Lee 2001.coke formation on the surface of $\mathrm{a} \mathrm{Al}_{2} \mathrm{O}_{3}$ in the catalytic pyrolysis of naphtha. Korean Journal of Chemical Engineering 18, 1842847. [CrossRef]. 
ASafavi, H.Abdollahi, 2001, Spectrophotometric study on micellemediated shift in kinetic and equilibrium of complex formation between $\mathrm{Ni}^{2+}$ and 2amino-cyclopentence-1-dithiocarboxylic acid.Microchemical Journal 69, 69-77. [CrossRef].

SenayTasioglu,

M.BurcuGurdere. 2000. Elucidtion of the mechanism of an aromatic substitution reaction by the utilization of micelles as mechanistic probes.Colloids and Surfaces A: Physicochemial and Engineering Aspects 173, 101-107. [CrossRef].

Kabir-ud-Din,

JamilK.J.Selem.Sanjeevkumar, Zaheer Khan. 1999. The Micelle-Induced Interaction between Ninhydrin and Tryptophan, Journal of colloid and Interface science 215,9-15. [CrossRef].

SenayTascioglu 1996. Micellar solutions as reaction media. Tetrahedron 52, 1111311152. [CrossRef].

Clifford A Bunton,Gianfranco Savelli Organic Reactivity in Aqueous Micelles and similar Assemblies 312-309. [CrossRef].

Clifford A Bunton, RaduBacloglu. 1987.Effects of submicellar aggregates on nucleophilic aromatic substitution and addition. Journal of Colloid and Interface Science 115,288-290.[CrossRef].

S. Tascioglu, Tetrahedron, 52,11113 (1996).
C.A. Bunton, V.S.Hong, L.S. Romsted, C.Quan.J.AmChem, soc. 103,5784 (1981).

H.Al- hohedan, C.A.Bunton, M.M.Mhala, J Am-Chem.soc, 104,6654 (1982).

C.A. Bunton, Adv. Chem.soc., 215,425 (1987).

R.A. moss, H.Qhang, S.chatterjee, K.K Jespersen, Tetrahedron Lett, 34,1729 (1993).

A.T. kotchewar,R.A. Moss, P. Scrimin., P.Tecilla., H.Zhang,Tetrhedron letters, 35,4927 (1994).

I.Herrold, S.P.,J.Colloid sci. 15,280 (1960).

E.Berliner,J.Am.Chem.soc.72,4003 (1950)

E.Berliner,J.Am.Chem.Eduec., 43,124,(1966).

R.C.Cambie, P.S. Rutledge, T.SmithPalmar,P.D., woodgate,J.Chem.soc.perkin trans. 1,1161 (1976).

G.corsaro,J.K.Smith,J.chem.Educ., 53,59 (1976).

V.T. Dangat, S.C. Bonde, A.S. Gayakhe, B.S Ghorpade, Indian J.chem., 28A, 321 (1989). 